\title{
Enhancing strength and ductility of Mg-Zn-Gd alloy via slow-speed extrusion combined with pre-forging
}

\author{
M.G. Jiang a, b, C. Xu ${ }^{\text {c }}$, T. Nakata ${ }^{\text {c }}$, H. Yan ${ }^{\text {a,* }}$, R.S. Chen ${ }^{\text {a,* }}$, S. Kamado ${ }^{c}$ \\ ${ }^{a}$ The Group of Magnesium Alloys and Their Applications, Institute of Metal Research, \\ Chinese Academy of Sciences, 62 Wencui Road, Shenyang 110016, China \\ ${ }^{\mathrm{b}}$ University of Chinese Academy of Sciences, 19 Yuquan Road, Beijing 100049, China \\ ${ }^{c}$ Department of Mechanical Engineering, Nagaoka University of Technology, Nagaoka \\ 940-2188, Japan
}

\begin{abstract}
Mg-1.58Zn-0.52Gd (wt.\%) alloy was subjected to slow-speed extrusion at $350{ }^{\circ} \mathrm{C}$ and $400{ }^{\circ} \mathrm{C}$ combined with hot pre-forging. The extruded alloy without pre-forging exhibited a bimodal microstructure, consisting of fine dynamically recrystallized (DRXed) grains and coarse unDRXed grains elongated along the extrusion direction, and strong basal texture, while pre-forging changed the bimodal structure into fully DRXed microstructure with finer grains and weaker extrusion texture. The fine and homogeneous extruded microstructure in the pre-forged alloy was mainly ascribed to the combined effect of refined starting microstructure just before extrusion, continuous DRX mechanism during extrusion and pinning effect induced by fine $\mathrm{Mg}_{3} \mathrm{Zn}_{3} \mathrm{Gd}_{2}$ precipitates. The pre-forged alloy exhibited superior balance of strength and ductility, as well as yield asymmetry, to the non-forged alloy after extrusion. The pre-forged alloy extruded at $350^{\circ} \mathrm{C}$ and $400{ }^{\circ} \mathrm{C}$ showed highly improved elongation of $27.9 \%$ and $34.8 \%$, respectively, mainly due to the formation of fully DRXed microstructure with fine grains through suppressing the activity of $\{10 \overline{1} 1\}$ contraction and $\{10 \overline{1} 1\}-\{10 \overline{1} 2\}$ double twins during tensile deformation.
\end{abstract}

Keywords : Magnesium alloy; Extrusion; Forging; Microstructure; Mechanical properties

* Corresponding authors. Tel.: +86-24-23926646; Fax: +86-24-23894149. E-mail addresses: hyan@imr.ac.cn (H. Yan), rschen@imr.ac.cn (R.S. Chen) 


\section{Introduction}

Magnesium ( $\mathrm{Mg})$ and its alloys have great potential applications in automotive, railway and aerospace industries, where there is a strong need to reduce weight and thus improve fuel efficiency. Currently, much more effort has been put into the applications of wrought $\mathrm{Mg}$ alloys, as these provide superior mechanical properties to cast alloys due to the eliminated casting defects and refined grain size. However, further improvement in strength and ductility of wrought $\mathrm{Mg}$ alloys are still needed to replace the commercially used aluminum alloys and steels.

Extrusion is the most commonly used and industrially viable thermomechanical process, and an effective approach to enhance the mechanical properties of $\mathrm{Mg}$ alloys. It is known that the microstructure and mechanical properties of extruded $\mathrm{Mg}$ alloys are closely related to the extrusion conditions, such as the temperature, speed and ratio [1-4]. During hot extrusion, dynamic recrystallization (DRX) occurs, leading to the development of fine grains. Generally, slow-speed extrusion $(\leq 5 \mathrm{~mm} / \mathrm{s})$ at relatively low temperature is utilized to achieve high strength by inhibiting the excessive growth of DRXed grains during deformation. However, the slow-speed extruded alloys usually exhibit a bimodal microstructure containing large areas of coarse unDRXed grains elongated along the extrusion direction (ED), which deteriorates the room temperature ductility due to the twinning activity during tensile deformation [5-7]. To overcome this issue, extensive effort has been directed toward obtaining fine and homogeneous grain structure by promoting DRX, and thus enhanced strength and ductility, such as double extrusion [8,9], aging prior to extrusion $[10,11]$ and cold forging prior to extrusion $[12,13]$. Park et al. $[12,13]$ reported that cold forging a homogenized billet at room temperature prior to extrusion can improve the tensile properties of extrudates by inducing numerous twins in the billet, which provided more nucleation sites for DRX during extrusion, leading to an increase in the DRX fraction of the extruded alloy. Despite the twin-aided DRX, however, fully DRXed microstructure was still difficult to be achieved due to the low extrusion temperature of $200{ }^{\circ} \mathrm{C}$, consequently resulting in undesirable ductility $(<20 \%)$. Besides, this 
method was only appropriate for low-temperature extrusion $\left(<250{ }^{\circ} \mathrm{C}\right)$ because the pre-induced twins could disappear before starting the extrusion at temperatures $>250$ ${ }^{\circ} \mathrm{C}$.

In our previous studies [14-18], a series of Mg-Zn-Gd alloys have been developed for hot rolling and extrusion as high ductile wrought $\mathrm{Mg}$ alloys. Recently, we optimized the alloy composition and developed high-speed extrudable Mg-1.58Zn-0.52Gd (wt.\%) alloy with improved room temperature ductility ( 30\%) due to weakened rare earth texture [18]. However, the extruded alloy exhibited quite low strength $(<100 \mathrm{MPa})$. In this study, therefore, slow-speed extrusion combined with hot pre-forging was applied to $\mathrm{Mg}-1.58 \mathrm{Zn}-0.52 \mathrm{Gd}$ (wt.\%) alloy with the aim of achieving superior balance of strength and ductility, as well as yield asymmetry, by forming fully DRXed microstructure with fine grains and weakened basal texture. Here, we adopted a novel multi-directional impact forging (MDIF) process with high strain rate as hot forging prior to extrusion, which was proposed in our previous studies [19-22] and showed high efficiency for grain refinement and great potential for large-scale industrial production. Meanwhile, the present study will try to understand the relation between pre-forging and extrusion temperature, and the influence of pre-forging on the DRX and texture development during extrusion.

\section{Experimental procedures}

Alloy ingot with a composition of $\mathrm{Mg}-1.58 \mathrm{Zn}-0.52 \mathrm{Gd}$ (wt.\%) was prepared by high purity $99.9 \% \mathrm{Mg}, 99.9 \% \mathrm{Zn}, 99.95 \% \mathrm{Gd}$ by resistance melting under the protection of a gas mixture of $\mathrm{SF}_{6}(1 \mathrm{Vol} . \%)$ and $\mathrm{CO}_{2}(99 \mathrm{Vol} . \%)$. The ingot was homogenized at $480{ }^{\circ} \mathrm{C}$ for $12 \mathrm{~h}$ and then quenched into hot water, and subsequently machined to cubic samples for forging $(60 \mathrm{~mm} \times 60 \mathrm{~mm} \times 60 \mathrm{~mm})$. MDIF process was performed using industrial air pneumatic hammer machine with load gravity of $250 \mathrm{Kg}$ and the detailed procedures have been described in our previous study [19-22]. In brief, the cubic samples were first heated to $300{ }^{\circ} \mathrm{C}$ in an electric resistant furnace and kept for $30 \mathrm{~min}$, and forged 30 passes followed by water-quenching. The forging direction was changed by $90^{\circ}$ pass by pass (i.e. $\mathrm{Z}$ to $\mathrm{Y}$ to $\mathrm{X}$ to $\mathrm{Z}$ to...) and no reheating process was 
employed during forging. The pre-forged and non-forged samples were machined into billets for extrusion (43 $\mathrm{mm}$ in diameter and $35 \mathrm{~mm}$ in height). These billets were heated at the extrusion temperatures of $350{ }^{\circ} \mathrm{C}$ and $400{ }^{\circ} \mathrm{C}$ for $5 \mathrm{~min}$ in the pre-heated container, and then extruded using indirect extrusion method under an extrusion ratio of 20 and a die-exit speed of $1.2 \mathrm{~m} / \mathrm{min}$.

The microstructures were observed using optical microscope (OM, Olympus BX51M), electron back-scatter diffraction (EBSD) and transmission electron microscope (TEM, JEOL JEM-2100F) equipped with energy-dispersive X-ray spectroscopy (EDX) operating at $200 \mathrm{kV}$. EBSD observation was conducted on a JEOL JSM-7000F FE-SEM equipped with an EDAX-TSL EBSD system operating at $15 \mathrm{kV}$. Grain sizes and textures were characterized by EBSD method and the data were analyzed with OIM Analysis software. To ensure the statistical rigor, more than 2000 grains were examined for each conditions. The microstructure of the forged sample was observed at the central part of the last forging plane containing the last forging direction. The DRX fraction was determined by an Image-Pro Plus 6.0 software using low magnified optical micrographs $(50 \times)$ taken at five different locations from the surface to the center in the extruded bar. Thin foil specimens for the TEM observations were prepared by punching $3 \mathrm{~mm}$ in diameter discs, mechanical polishing and ion milling using a Gatan Precision Ion Polishing System (GATAN691). The mechanical properties were evaluated by tensile and compressive tests using a Shimadzu Autograph AG-I $(50 \mathrm{kN})$ at room temperature under an initial strain rate of $1.0 \times 10^{-3} \mathrm{~s}^{-1}$ with the stress direction parallel to the ED. The tensile specimens were $4 \mathrm{~mm}$ in diameter and $22 \mathrm{~mm}$ in gauge length and the compressive specimens were $4 \mathrm{~mm}$ in diameter and $10 \mathrm{~mm}$ in height.

\section{Results and discussion}

\subsection{Microstructure and texture before extrusion}

The microstructural observation of the as-homogenized alloy reveals that the initial grains were very coarse and inhomogeneous, and some grains were as large as $\sim 2 \mathrm{~mm}$, which was not presented here. Fig. 1 shows the EBSD observation results of the 
pre-forged alloy. It can be observed that high density of twins activated, and all the twins were identified to be $\{10 \overline{1} 2\}$ extension twins with a misorientation of $86.3 \pm 5^{\circ}$, whereas $\{10 \overline{1} 1\}$ contraction twins were absent as observed in Mg-Gd-Y alloy [22]. This high activity of $\{10 \overline{1} 2\}$ twins can be attributed to the high strain-rate deformation and continuous change of forging direction during pre-forging process $[20,21]$. Additionally, many fine DRXed grains of $\sim 1 \mu \mathrm{m}$ were observed in the pre-forged alloy, since $\{10 \overline{1} 2\}$ extension twin boundaries could effectively block the dislocation motion and facilitate the formation of subgrain structure, finally leading to the development of fine DRXed grains [20,21]. Fig. 2 shows the EBSD observation results of the pre-forged alloy just after heating at $350{ }^{\circ} \mathrm{C}$ and $400{ }^{\circ} \mathrm{C}$ for $5 \mathrm{~min}$ before extrusion. Despite the short time heating prior to extrusion, static recrystallization (SRX) took place, giving rise to a significantly refined microstructure without any $\{10 \overline{1} 2\}$ extension twins. It is noted that the grain structure was not homogeneous, especially after heating at $350^{\circ} \mathrm{C}$, and many low angle grain boundaries (LAGBs) were observed in relatively coarse grains (indicated by black arrows in Fig 2a and b). The distinct peaks in the range of $2-10^{\circ}$ in the misorientation angle distribution (Fig. 2c) suggest that SRX has not completely taken place. As seen in Fig. 2d, the average grain size after heating at $350{ }^{\circ} \mathrm{C}(14.5 \mu \mathrm{m})$ was slightly finer than that after heating at $400{ }^{\circ} \mathrm{C}(19.9 \mu \mathrm{m})$. Similar to the as-homogenized state, the pre-forged alloy showed random textures just before extrusion, as shown in (0001) pole figures (Fig. 2a and b). It can be expected that the much refined microstructure obtained just before extrusion will greatly influence the resultant microstructure and mechanical properties of the extruded Mg-Zn-Gd alloy.

\subsection{Microstructure and texture after extrusion}

Fig. 3 shows the inverse pole figure maps of the alloy extruded at $350{ }^{\circ} \mathrm{C}$ and 400 ${ }^{\circ} \mathrm{C}$ without and with pre-forging. The extruded alloy without pre-forging exhibited a typical bimodal grain structure consisting of fine equiaxial DRXed grains and coarse unDRXed grains elongated along the ED (indicated by the white arrows in Fig. 3a and 
b). With increasing extrusion temperature, the DRX faction increased from 0.66 to 0.85 and the DRXed grain size increased from $3.1 \mu \mathrm{m}$ to $12.2 \mu \mathrm{m}$. As for the alloy with pre-forging, the DRX fraction significantly increased with the bimodal structure changing into fine and homogeneous microstructure. The pre-forged alloy extruded at $350{ }^{\circ} \mathrm{C}$ showed an almost fully DRXed microstructure with few unDRXed grains (indicated by white arrows in Fig. 3c) and similar DRXed grain size $(\sim 3.7 \mu \mathrm{m})$ with the non-forged alloy $(\sim 3.1 \mu \mathrm{m})$. After extrusion at $400{ }^{\circ} \mathrm{C}$, the pre-forged alloy showed a fully DRXed microstructure with finer DRXed grain size $(9.7 \mu \mathrm{m})$ than the non-forged alloy $(12.2 \mu \mathrm{m})$.

Shown in Fig. 4 are the TEM observation results of the alloy extruded at $350{ }^{\circ} \mathrm{C}$ without and with pre-forging. TEM bright field (BF) image (Fig. 4a) exhibits the coexistent morphology of fine DRXed and coarse unDRXed grain regions in the non-forged alloy. In the DRXed grain region (Fig. 4b), fine DRXed grains of $\sim 1 \mu \mathrm{m}$ was observed with numerous spherical particles dynamically precipitating at the DRXed grain boundaries (GBs) and within the grain interiors. In the unDRXed grain region (Fig. 4c), high density of dislocations in the form of dislocation walls were observed, indicating the occurrence of dislocation rearrangement during extrusion. Inspection of the corresponding high-angle annular dark-field (HAADF) image (Fig. 4d) revealed that fine spherical precipitates also dispersed homogeneously throughout the unDRXed grain region. For the pre-forged alloy extruded at $350{ }^{\circ} \mathrm{C}$ (Fig. 4e), the DRXed grain size was slightly increased, being consistent with the EBSD observation, and many dynamic precipitates were observed as well. It becomes much clear in the enlarged HAADF image (Fig. 4f) that fine spherical particles with size of 5-50 nm dynamically precipitated during extrusion. In the corresponding EDX elemental mappings (Fig. $4 \mathrm{~g}$ and $\mathrm{h}$ ), it is obvious that these particles were enriched with $\mathrm{Zn}$ and Gd elements. The $\mathrm{Zn} / \mathrm{Gd}$ (at.\%) value was measured to be about 2.7 by EDX point analysis. According to our previous studies on Mg-Zn-Gd ternary alloys $[14,17,18]$, these fine spherical precipitates were expected to be $\mathrm{Mg}_{3} \mathrm{Zn}_{3} \mathrm{Gd}_{2}$ (w-phase) phase, which has a face centered cubic (fcc) structure and a composition close to $\mathrm{MgZn}_{2} \mathrm{Gd}$ [23]. After extrusion at $400{ }^{\circ} \mathrm{C}$ (Fig. 5), fine $\mathrm{Mg}_{3} \mathrm{Zn}_{3} \mathrm{Gd}_{2}$ phase particles were also 
detected at the DRXed GBs and within the grain interiors in both non-forged and pre-forged alloy, whereas the density drastically decreased compared to that in the alloy extruded at $350{ }^{\circ} \mathrm{C}$. It is suggested that these dynamic precipitates are effective in suppressing the grain growth during hot extrusion, resulting in the refinement of DRXed grains. This pinning effect of particles would be much evident during extrusion at $350{ }^{\circ} \mathrm{C}$ due to the high density of precipitates.

Fig. 6 shows the textures of the alloy extruded at $350{ }^{\circ} \mathrm{C}$ and $400{ }^{\circ} \mathrm{C}$ without and with pre-forging. The (0001) pole figures reveal that the alloy had typical extrusion basal texture, in which basal planes were preferentially aligned parallel to the ED, irrespective of the pre-forging process. Apparently, the pre-forged alloy exhibited much weaker basal texture than non-forged alloy. Besides, the maximum texture intensity decreased with a rise in extrusion temperature. To further identify the texture characteristic, the crystallographic orientations of the DRXed and unDRXed grains were separately analyzed by EBSD and highlighted by red and blue points, respectively, and the results are presented in Fig. $6 \mathrm{~b}, \mathrm{~d}, \mathrm{f}$ and $\mathrm{h}$. It is clear that the unDRXed grains were strongly textured with $[10 \overline{1} 0]$ orientation parallel to the ED, whereas the DRXed grains showed a large spread in orientation, indicating that the orientation of the unDRXed grains gave rise to the strong intensity for extrusion basal texture, which is consistent with the previous studies [24-27].

To investigate the influence of pre-forging on the DRX process and texture development during hot extrusion, microstructures were observed near the die exit in the alloy extruded at $400{ }^{\circ} \mathrm{C}$ without and with pre-forging using OM and EBSD, and the results are presented in Fig. 7 and 8. The low magnified optical microstructures at large area near the die exit (Fig. 7) clearly show that very coarse unDRXed grain regions aligned with the material flow toward the die exit during extrusion in the non-forged alloy, as indicated by blue arrows, and these regions still existed after passage through the die. In comparison, the pre-forged alloy showed significantly decreased unDRXed grain regions during extrusion and nearly no such regions were observed at the die exit. Fig. 8 shows the EBSD observation results at location of 5 
$\mathrm{mm}$ to the die exit. In the inverse pole figure maps (Fig. 8a and e), it is evident that the non-forged alloy showed much higher fraction of unDRXed grains than the pre-forged alloy and large numbers of LAGBs were observed in the unDRXed grains, which can be further confirmed from the high peak in the misorientation angle distributions (Fig. 8b and f). Usually, LAGBs result from accumulated dislocations and formation of sub-GBs in the deformed structure $[28,29]$. The line profiles of point-to-origin along the black arrows $\mathrm{AB}$ (Fig. 8c and g) in the inverse pole figure maps show a continuous increase of misorientation angle, indicating that the unDRXed grains were experiencing a gradual change of orientation due to the pile-up dislocations that rearranged themselves to form groups of dislocation walls, i.e. LAGBs, as observed in Fig. 4c. Careful examination of the inverse pole figure maps indicated that many subgrains or substructures surrounded by LAGBs formed in the vicinity of the boundaries of the elongated unDRXed grains, as indicated by the red arrows in Fig. 8a and e. With increasing strain, more mobile dislocations would be trapped by the LAGBs and these LAGBs transform into high angle grain boundaries (HAGBs), eventually turning the subgrains into new DRXed grains. Such kind of formation of new DRXed grains is classified as continuous DRX (CDRX) mechanism [30-33]. Furthermore, the separately analyzed (0001) pole figures of the DRXed and unDRXed grains (Fig. 8d and h) show that the unDRXed grains retained the strong deformation texture, i.e. $<10 \overline{1} 0>$ fiber texture and the DRXed grains resulted in the randomization of grain orientations. As a result, the much weakened basal texture has already formed before passing through the die in the alloy with pre-forging because of the drastic decrease of unDRXed grains. The above observations point to the fact that fine DRXed grains newly formed and progressively consumed the coarse unDRXed grains during hot extrusion via CDRX mechanism in Mg-Zn-Gd alloy irrespective of the initial state of the alloy, and the pre-forging could effectively lead to the development of fine and homogeneous grain structure and weakened extrusion texture by refining the starting microstructure before extrusion and thus reducing the unDRXed grains during extrusion. 


\subsection{Mechanical properties after extrusion}

Fig. 9 shows the tensile and compressive stress-strain curves of the alloy extruded at $350{ }^{\circ} \mathrm{C}$ and $400{ }^{\circ} \mathrm{C}$ without and with pre-forging. To describe and compare the mechanical properties conveniently, the relavent data are listed in Table. 1. The pre-forged alloy exhibited superior balance of strength and ductility, as well as low yield asymmetry, to the non-forged alloy after extrusion. After extrusion at $350{ }^{\circ} \mathrm{C}$, the non-forged alloy showed high tensile yield strength (TYS) of $283 \mathrm{MPa}$, ultimate tensile strength (UTS) of $295 \mathrm{MPa}$, and low elongation of $10.0 \%$, while the pre-forged alloy showed slightly decreased TYS of $254 \mathrm{MPa}$, UTS of $284 \mathrm{MPa}$ and highly improved elongation of $27.9 \%$. With increasing extrusion temperature, the elongation further increased with sacrifice of YTS and UTS for both non-forged and pre-forged alloy. After extrusion at $400{ }^{\circ} \mathrm{C}$, pre-forging resulted in synchronously enhanced strength and ductility with TYS of $181 \mathrm{MPa}$, UTS of $248 \mathrm{MPa}$ and elongation of $34.8 \%$, compared to the non-forged alloy. In addition, higher compressive yield strength (CYS) was obtained, as well as lower yield asymmetry with CYS/TYS ratio of $\sim 0.75$, in the pre-forged alloy after extrusion at $350{ }^{\circ} \mathrm{C}$ and $400{ }^{\circ} \mathrm{C}$.

As evidenced from Table. 1, the mechanical properties are strongly dependent on the initial state of the alloy, extrusion temperature and the resultant microstructural characteristics. The extruded alloy without pre-forging, as already described, exhibited a bimodal grain structure that consisted of fine DRXed grains and coarse unDRXed grains along the ED and strong basal texture, while the extruded alloy with pre-forging showed a fully DRXed microstructure and weakened basal texture. This has significant consequences for the strength and ductility, as well as mechanical anisotropy mainly due to the combined effect of grain size from Hall-Petch relation and extrusion texture through its effect on the activation of slip system and twinning [34-36].

Since the dominant deformation modes in $\mathrm{Mg}$ alloys at room temperature are basal slip system and $\{10 \overline{1} 2\}$ extension twin, the Schmid factor distribution histogram for

$(0001)<11 \overline{2} 0>$ basal slip when tension along the ED and $(10 \overline{1} 2)<10 \overline{1} \overline{1}>$ extension 
twin when compression along the ED were analyzed by EBSD, as shown in Fig. 10. The average Schmid factor for basal slip of the non-forged and pre-forged alloy extruded at $350{ }^{\circ} \mathrm{C}$ was only 0.14 and 0.17 , respectively, suggesting the difficulty of basal slip activation. Hence, the higher TYS of the alloy extruded at $350{ }^{\circ} \mathrm{C}$ can be ascribed to finer DRXed grains (Fig. 3), stronger basal texture (Fig. 6) or lower Schmid factor for basal slip (Fig. 10a) and higher density of dynamic precipitates (Fig. 4 and 5). As stated earlier, the effect of pre-forging on the resulting tensile strength at different extrusion temperature was quite different. From the Schmid factor distribution histogram for basal slip (Fig. 10a), it can be determined that the pre-forged alloy had higher average Schmid factor than the non-forged alloy after extrusion at the same temperature due to the weakened basal texture, which indicates the less contribution of texture strengthening to the yield strength in the pre-forged alloy. Hence for the alloy extruded at $350{ }^{\circ} \mathrm{C}$, the lower TYS in the pre-forged alloy was the result of easier operation of basal slip and deficiency of the unDRXed grains with high defect density (Fig. 4), while for the alloy extruded at $400{ }^{\circ} \mathrm{C}$, the higher TYS in the pre-forged alloy was mainly ascribed to its refined DRXed grain size (Fig. 3). Recently, the segregation of $\mathrm{Gd}, \mathrm{Zn}$ or both at GBs or twin boundaries and the solute clustering within the matrix have been observed in Mg-Gd binary or Mg-Zn-Gd ternary alloys [37-41]. What's more, Nie et al. [37] previously proposed that the co-segregation of $\mathrm{Gd}$ and $\mathrm{Zn}$ atoms in the form of dimers can provide more effective pinning of gliding dislocations, thus contributing to the large hardness increase. In this case, therefore, similar effect of the solute segregation can be expected to contribute to the strength enhancement of the extruded Mg-Zn-Gd alloy. On the other hand, all the samples presented severe concave-shaped compressive curves during the early stage of deformation (Fig. 9b), which is known to be a typical feature of $\{10 \overline{1} 2\}$ extension twinning dominated deformation [42-44]. This behavior can be understood from the high average Schmid factor for $\{10 \overline{1} 2\}$ extension twin when compression along the ED (Fig. 10b). It is known that the $\{10 \overline{1} 2\}$ extension twinning is much easily activated in coarse unDRXed grains of extruded Mg alloys during compressive 
deformation along the ED due to their strong $<10 \overline{1} 0>$ fiber texture and large grain size. Furthermore, numerous fine dynamic precipitates in the unDRXed grains (Fig. 4d) may promote the twin nucleation based on the previous studies reported by Stanford et al. $[45,46]$. As the easy formation of $\{10 \overline{1} 2\}$ extension twins usually decreases the yield strength during compression [47,48], extrusion combined with pre-forging gave rise to the increased CYS and thus improved yield asymmetry by reducing the unDRXed grains with numerous fine particles and finally forming fully DRXed microstructure.

Fig. 11 shows optical microstructures of fractured tensile specimens of the alloy extruded at $350{ }^{\circ} \mathrm{C}$ and $400{ }^{\circ} \mathrm{C}$ without and with pre-forging. It is evident that the fracture mechanism was completely different for the extruded alloy without and with pre-forging. As indicated by red arrows in Fig. 11a and b, it can be seen that micro-cracks initiated at the twins formed within coarse unDRXed grains in the extruded alloy without pre-forging. Previous studies have reported that the ductility of the extruded $\mathrm{Mg}$ alloys is strongly dependent on the fraction of coarse unDRXed grains [5-7], because $\{10 \overline{1} 1\}$ contraction and $\{10 \overline{1} 1\}-\{10 \overline{1} 2\}$ double twins are easily formed in these unDRXed grains at the late stage of tensile deformation along the ED and their formation tends to be initiation sites for micro-cracks through dislocation pile-ups at the twin-matrix interface, thereby deteriorating the ductility $[49,50]$. Besides, $\{10 \overline{1} 1\}$ contraction and $\{10 \overline{1} 1\}-\{10 \overline{1} 2\}$ double twins become more difficult to be generated in fine DRXed grains despite the favorable grain orientations, because the activation stress for twinning increases markedly with grain size drop [51,52]. Hence, highly improved ductility was obtained in the pre-forged alloy after extrusion due to the formation of fully DRXed microstructure with fine grains, which suppressed the activity of $\{10 \overline{1} 1\}$ contraction and $\{10 \overline{1} 1\}-\{10 \overline{1} 2\}$ double twins during tensile deformation. On the other hand, it is proposed that fine grains $(<10 \mu \mathrm{m})$ greatly contribute to the ductility improvement in $\mathrm{Mg}$ alloys due to the grain-boundary compatibility stress that can extend across the entire grain and further 
activate non-basal slip [53]. This grain size effect becomes much evident in the pre-forged alloy extruded at $350{ }^{\circ} \mathrm{C}$ with fine DRXed grains of $\sim 3.7 \mu \mathrm{m}$, contributing to a drastic improvement in ductility from $10.0 \%$ to $27.9 \%$. Besides, the obtained weakened basal texture after extrusion with pre-forging, which favored the operation of basal slip when tension along the ED, is also another important contributor to the ductility improvement.

Based on the above discussion, therefore, it can be concluded that slow-speed extrusion combined with pre-forging is an effective and promising method to synchronously enhance the strength and ductility of Mg-1.58Zn-0.52Gd (wt.\%) alloy, as well as yield asymmetry, by forming fully recrystallized microstructure with fine DRXed grains and weakened basal texture. It is noted that this method is not confined to the Mg-Zn-Gd alloy used in the present study and is expected to be available in other $\mathrm{Mg}$ alloy systems, especially those that have initial coarse as-cast grains and/or contain rare earth (RE) element, considering the effect of RE on retarding the DRX of Mg alloys during extrusion [54,55].

\section{Conclusions}

The Mg-1.58Zn-0.52Gd (wt.\%) alloy was subjected to slow-speed extrusion at 350 ${ }^{\circ} \mathrm{C}$ and $400{ }^{\circ} \mathrm{C}$ combined with hot pre-forging to synchronously enhance the strength and ductility, as well as yield asymmetry. Besides, the influence of pre-forging on the DRX and texture development during extrusion was investigated. The main conclusions are summarized as follows:

(1) After extrusion, the non-forged alloy exhibited a typical bimodal grain structure consisting of fine DRXed grains and coarse unDRXed grains elongated along the ED, while pre-forging changed the bimodal structure into fully DRXed microstructure with finer grains. The non-forged and pre-forged alloy both had typical extrusion basal texture, but the pre-forged alloy showed much weakened

basal texture due to the reduced unDRXed grains with strong [10 $\overline{1} 0]$ orientation parallel to the ED. 
(2) Fine $\mathrm{Mg}_{3} \mathrm{Zn}_{3} \mathrm{Gd}_{2}$ phase dynamically precipitated during hot extrusion and their density decreased with a rise in extrusion temperature. It is suggested that these precipitates are effective pinning obstacles for inhibiting the DRXed grain growth during extrusion, especially at $350{ }^{\circ} \mathrm{C}$, contributing to the grain refinement.

(3) CDRX mechanism played dominant roles during extrusion for both non-forged and pre-forged alloy, by which fine DRXed grains newly formed and progressively consumed the coarse unDRXed grains during deformation.

(4) The pre-forged alloy exhibited superior balance of strength and ductility, as well as yield asymmetry, to the non-forged alloy after extrusion. Compared to the non-forged alloy, the pre-forged alloy extruded at $350{ }^{\circ} \mathrm{C}$ and $400{ }^{\circ} \mathrm{C}$ showed highly improved elongation of $27.9 \%$ and $34.8 \%$, respectively, mainly due to the formation of fully DRXed microstructure with fine grains through suppressing the activity of $\{10 \overline{1} 1\}$ contraction and $\{10 \overline{1} 1\}-\{10 \overline{1} 2\}$ double twins during tensile deformation.

\section{Acknowledgments}

The authors gratefully acknowledge the financial supports from the State Key Program of National Natural Science of China (No. 51531002), National Natural Science Foundation of China (NSFC, No. 51601193 and 51301173), National Key Research and Development Program of China (No. 2016YFB0301104), National Basic Research Program of China (973 Program, No. 2013CB632202), JST, Advanced Low Carbon Technology Research and Development Program (ALC A, No. 12102886) and JSPS, Grant-in-Aid for Young Scientists (B) (No. 16K18266). 


\section{References}

[1] F. Elsayed, T. Sasaki, T. Ohkubo, H. Takahashi, S. Xu, S. Kamado, K. Hono, Effect of extrusion conditions on microstructure and mechanical properties of microalloyed Mg-Sn-Al-Zn alloys, Mater. Sci. Eng. A 588 (2013) 318-328.

[2] S.H. Park, B.S. You, R.K. Mishra, A.K. Sachdev, Effects of extrusion parameters on the microstructure and mechanical properties of $\mathrm{Mg}-\mathrm{Zn}-(\mathrm{Mn})-\mathrm{Ce} / \mathrm{Gd}$ alloys, Mater. Sci. Eng. A 598 (2014) 396-406.

[3] J. Wang, Z. Wu, S. Gao, R. Lu, D. Qin, W. Yang, F. Pan, Optimization of mechanical and damping properties of $\mathrm{Mg}-0.6 \mathrm{Zr}$ alloy by different extrusion processing, J. Magnes. Alloys 3 (2015) 79-85.

[4] Y.Z. Du, X.G. Qiao, M.Y. Zheng, K. Wu, S.W. Xu, Development of high-strength, low-cost wrought $\mathrm{Mg}-2.5$ mass\% $\mathrm{Zn}$ alloy through micro-alloying with $\mathrm{Ca}$ and $\mathrm{La}$, Mater. Des. 85 (2015) 549-557.

[5] H. Yu, S. Hyuk Park, B. Sun You, Y. Min Kim, H. Shun Yu, S. Soo Park, Effects of extrusion speed on the microstructure and mechanical properties of ZK60 alloys with and without $1 \mathrm{wt} \%$ cerium addition, Mater. Sci. Eng. A 583 (2013) 25-35.

[6] S.W. Xu, M.Y. Zheng, S. Kamado, K. Wu, G.J. Wang, X.Y. Lv, Dynamic microstructural changes during hot extrusion and mechanical properties of a Mg-5.0 Zn-0.9 Y-0.16 Zr (wt.\%) alloy, Mater. Sci. Eng. A 528 (2011) 4055-4067.

[7] S.H. Park, B.S. You, Effect of homogenization temperature on the microstructure and mechanical properties of extruded Mg-7Sn-1 Al-1Zn alloy, J. Alloys Compd. 637 (2015) 332-338.

[8] S.-k. Guan, S.-j. Zhu, L.-g. Wang, Q. Yang, W.-b. Cao, Microstructures and mechanical properties of double hot-extruded AZ80+xSr wrought alloys, Trans. Nonferr. Met. Soc. China 17 (2007) 1143-1151.

[9] X. Zhang, Z. Wang, G. Yuan, Y. Xue, Improvement of mechanical properties and corrosion resistance of biodegradable $\mathrm{Mg}-\mathrm{Nd}-\mathrm{Zn}-\mathrm{Zr}$ alloys by double extrusion, Mater. Sci. Eng. B 177 (2012) 1113-1119.

[10] J.-G. Jung, S.H. Park, H. Yu, Y.M. Kim, Y.-K. Lee, B.S. You, Improved mechanical properties of $\mathrm{Mg}-7.6 \mathrm{Al}-0.4 \mathrm{Zn}$ alloy through aging prior to extrusion, Scr. Mater. 93 (2014) 8-11.

[11] J.-G. Jung, S.H. Park, B.S. You, Effect of aging prior to extrusion on the microstructure and mechanical properties of $\mathrm{Mg}-7 \mathrm{Sn}-1 \mathrm{Al}-1 \mathrm{Zn}$ alloy, J. Alloys Compd. 627 (2015) 324-332.

[12] S.H. Park, H.S. Kim, J.H. Bae, C.D. Yim, B.S. You, Improving the mechanical properties of extruded Mg-3Al-1Zn alloy by cold pre-forging, Scr. Mater. 69 (2013) 250-253.

[13] S.H. Park, J.H. Lee, H. Yu, J. Yoon, B.S. You, Effect of cold pre-forging on the microstructure and mechanical properties of extruded $\mathrm{Mg}-8 \mathrm{Sn}-1 \mathrm{Al}-1 \mathrm{Zn}$ alloy, Mater. Sci. Eng. A 612 (2014) 197-201.

[14] H. Yan, R.S. Chen, E.H. Han, Room-temperature ductility and anisotropy of two rolled Mg-Zn-Gd alloys, Mater. Sci. Eng. A 527 (2010) 3317-3322.

[15] D. Wu, R.S. Chen, W.N. Tang, E.H. Han, Influence of texture and grain size on 
the room-temperature ductility and tensile behavior in a $\mathrm{Mg}-\mathrm{Gd}-\mathrm{Zn}$ alloy processed by rolling and forging, Mater. Des. 41 (2012) 306-313.

[16] H. Yan, R. Chen, N. Zheng, J. Luo, S. Kamado, E. Han, Effects of trace Gd concentration on texture and mechanical properties of hot-rolled $\mathrm{Mg}-2 \mathrm{Zn}-\mathrm{xGd}$ sheets, J. Magnes. Alloys 1 (2013) 23-30.

[17] J. Luo, H. Yan, R.-S. Chen, E.-H. Han, Effects of Gd concentration on microstructure, texture and tensile properties of $\mathrm{Mg}-\mathrm{Zn}-\mathrm{Gd}$ alloys subjected to large strain hot rolling, Mater. Sci. Eng. A 614 (2014) 88-95.

[18] M.G. Jiang, C. Xu, T. Nakata, H. Yan, R.S. Chen, S. Kamado, Rare earth texture and improved ductility in a Mg-Zn-Gd alloy after high-speed extrusion, Mater. Sci. Eng. A 667 (2016) 233-239.

[19] M.G. Jiang, H. Yan, R.S. Chen, Enhanced mechanical properties due to grain refinement and texture modification in an AZ61 Mg alloy processed by small strain impact forging, Mater. Sci. Eng. A 621 (2015) 204-211.

[20] M.G. Jiang, H. Yan, R.S. Chen, Twinning, recrystallization and texture development during multi-directional impact forging in an AZ61 Mg alloy, J. Alloys Compd. 650 (2015) 399-409.

[21] M.G. Jiang, H. Yan, R.S. Chen, Microstructure, texture and mechanical properties in an as-cast AZ61 Mg alloy during multi-directional impact forging and subsequent heat treatment, Mater. Des. 87 (2015) 891-900.

[22] J.L. Li, D. Wu, Q.B. Yang, R.S. Chen, Superplasticity of multi-directional impact forged Mg-Gd-Y-Zr alloy, J. Alloys Compd. 672 (2016) 27-35.

[23] Y. Liu, G. Yuan, C. Lu, W. Ding, Stable icosahedral phase in Mg-Zn-Gd alloy, Scr. Mater. 55 (2006) 919-922.

[24] S.W. Xu, K. Oh-Ishi, S. Kamado, F. Uchida, T. Homma, K. Hono, High-strength extruded Mg-Al-Ca-Mn alloy, Scr. Mater. 65 (2011) 269-272.

[25] J. Hofstetter, S. Rüedi, I. Baumgartner, H. Kilian, B. Mingler, E. Povoden-Karadeniz, S. Pogatscher, P.J. Uggowitzer, J.F. Löffler, Processing and microstructure-property relations of high-strength low-alloy (HSLA) $\mathrm{Mg}-\mathrm{Zn}-\mathrm{Ca}$ alloys, Acta Mater. 98 (2015) 423-432.

[26] T.T. Sasaki, F.R. Elsayed, T. Nakata, T. Ohkubo, S. Kamado, K. Hono, Strong and ductile heat-treatable $\mathrm{Mg}-\mathrm{Sn}-\mathrm{Zn}-\mathrm{Al}$ wrought alloys, Acta Mater. 99 (2015) 176-186.

[27] Y.Z. Du, X.G. Qiao, M.Y. Zheng, D.B. Wang, K. Wu, I.S. Golovin, Effect of microalloying with $\mathrm{Ca}$ on the microstructure and mechanical properties of Mg-6 mass\%Zn alloys, Mater. Des. 98 (2016) 285-293.

[28] Y.C. Xin, M.Y. Wang, Z. Zeng, G.J. Huang, Q. Liu, Tailoring the texture of magnesium alloy by twinning deformation to improve the rolling capability, Scr. Mater. 64 (2011) 986-989.

[29] J. Luo, W.W. Hu, Q.Q. Jin, H. Yan, R.S. Chen, Unusual cold rolled texture in an Mg-2.0Zn-0.8Gd sheet, Scr. Mater. 127 (2017) 146-150.

[30] A. Galiyev, R. Kaibyshev, G. Gottstein, Correlation of plastic deformation and dynamic recrystallization in magnesium alloy Zk60, Acta Mater. 49 (2001) 1199-1207. 
[31] O. Sitdikov, R. Kaibyshev, Dynamic recrystallization in pure magnesium, Mater. Trans. 42 (2001) 1928-1937.

[32] M. Myshlyaev, H. McQueen, A. Mwembela, E. Konopleva, Twinning, dynamic recovery and recrystallization in hot worked $\mathrm{Mg}-\mathrm{Al}-\mathrm{Zn}$ alloy, Mater. Sci. Eng. A 337 (2002) 121-133.

[33] A. Beer, M. Barnett, Microstructural development during hot working of Mg-3Al-1Zn, Metall. Mater. Trans. A 38 (2007) 1856-1867.

[34] S. Agnew, M. Yoo, C. Tome, Application of texture simulation to understanding mechanical behavior of $\mathrm{Mg}$ and solid solution alloys containing Li or Y, Acta Mater. 49 (2001) 4277-4289.

[35] J. Del Valle, F. Carreño, O.A. Ruano, Influence of texture and grain size on work hardening and ductility in magnesium-based alloys processed by ECAP and rolling, Acta Mater. 54 (2006) 4247-4259.

[36] S.H. Choi, E.J. Shin, B.S. Seong, Simulation of deformation twins and deformation texture in an AZ31 Mg alloy under uniaxial compression, Acta Mater. 55 (2007) 4181-4192.

[37] J.F. Nie, K. Oh-ishi, X. Gao, K. Hono, Solute segregation and precipitation in a creep-resistant Mg-Gd-Zn alloy, Acta Mater. 56 (2008) 6061-6076.

[38] J. Nie, Y. Zhu, J. Liu, X.-Y. Fang, Periodic segregation of solute atoms in fully coherent twin boundaries, Science 340 (2013) 957-960.

[39] N. Stanford, G. Sha, J. Xia, S. Ringer, M. Barnett, Solute segregation and texture modification in an extruded magnesium alloy containing gadolinium, Scr. Mater. 65 (2011) 919-921.

[40] J.P. Hadorn, T.T. Sasaki, T. Nakata, T. Ohkubo, S. Kamado, K. Hono, Solute clustering and grain boundary segregation in extruded dilute $\mathrm{Mg}-\mathrm{Gd}$ alloys, Scr. Mater. 93 (2014) 28-31.

[41] M. Bugnet, A. Kula, M. Niewczas, G.A. Botton, Segregation and clustering of solutes at grain boundaries in Mg-rare earth solid solutions, Acta Mater. 79 (2014) 66-73.

[42] F. Zhang, M. Hao, F. Wang, C. Tan, X. Yu, H. Ma, H. Cai, Role of $\{10-12\}$ twinning and detwinning in the shock-hardening behavior of rolled $\mathrm{Mg}-3 \mathrm{Al}-1 \mathrm{Zn}$ alloy, Scr. Mater. 67 (2012) 951-954.

[43] B. Song, N. Guo, T. Liu, Q. Yang, Improvement of formability and mechanical properties of magnesium alloys via pre-twinning: A review, Mater. Des. 62 (2014) 352-360.

[44] L.B. Tong, M.Y. Zheng, S. Kamado, D.P. Zhang, J. Meng, L.R. Cheng, H.J. Zhang, Reducing the tension-compression yield asymmetry of extruded $\mathrm{Mg}-\mathrm{Zn}-\mathrm{Ca}$ alloy via equal channel angular pressing, J. Magnes. Alloys 3 (2015) 302-308.

[45] N. Stanford, M. Barnett, Effect of particles on the formation of deformation twins in a magnesium-based alloy, Mater. Sci. Eng. A 516 (2009) 226-234.

[46] J. Robson, N. Stanford, M. Barnett, Effect of particles in promoting twin nucleation in a Mg-5wt.\% Zn alloy, Scr. Mater. 63 (2010) 823-826.

[47] T. Homma, C.L. Mendis, K. Hono, S. Kamado, Effect of $\mathrm{Zr}$ addition on the mechanical properties of as-extruded $\mathrm{Mg}-\mathrm{Zn}-\mathrm{Ca}-\mathrm{Zr}$ alloys, Mater. Sci. Eng. A 527 
(2010) 2356-2362.

[48] S. Xu, K. Oh-ishi, H. Sunohara, S. Kamado, Extruded Mg-Zn-Ca-Mn alloys with low yield anisotropy, Mater. Sci. Eng. A 558 (2012) 356-365.

[49] M.R. Barnett, Twinning and the ductility of magnesium alloys Part II. "Contraction" twins, Mater. Sci. Eng. A 464 (2007) 8-16.

[50] P. Cizek, M.R. Barnett, Characteristics of the contraction twins formed close to the fracture surface in $\mathrm{Mg}-3 \mathrm{Al}-1 \mathrm{Zn}$ alloy deformed in tension, Scr. Mater. 59 (2008) 959-962.

[51] M.R. Barnett, Z. Keshavarz, A.G. Beer, D. Atwell, Influence of grain size on the compressive deformation of wrought $\mathrm{Mg}-3 \mathrm{Al}-1 \mathrm{Zn}$, Acta Mater. 52 (2004) 5093-5103.

[52] Y. Xin, X. Zhou, L. Lv, Q. Liu, The influence of a secondary twin on the detwinning deformation of a primary twin in $\mathrm{Mg}-3 \mathrm{Al}-1 \mathrm{Zn}$ alloy, Mater. Sci. Eng. A 606 (2014) 81-91.

[53] J. Koike, T. Kobayashi, T. Mukai, H. Watanabe, M. Suzuki, K. Maruyama, K. Higashi, The activity of non-basal slip systems and dynamic recovery at room temperature in fine-grained AZ31B magnesium alloys, Acta Mater. 51 (2003) 2055-2065.

[54] B. Wu, Y. Zhao, X. Du, Y. Zhang, F. Wagner, C. Esling, Ductility enhancement of extruded magnesium via yttrium addition, Mater. Sci. Eng. A 527 (2010) 4334-4340.

[55] H. Yan, S.W. Xu, R.S. Chen, S. Kamado, T. Honma, E.H. Han, Twins, shear bands and recrystallization of a $\mathrm{Mg}-2.0 \% \mathrm{Zn}-0.8 \% \mathrm{Gd}$ alloy during rolling, Scr. Mater. 64 (2011) 141-144. 


\section{Table Caption}

Table 1. Microstructural charateristics and mechanical properties of the alloy extruded at $350{ }^{\circ} \mathrm{C}$ and $400{ }^{\circ} \mathrm{C}$ without and with pre-forging.

\section{Figure Captions}

Fig. 1 EBSD observation results of the pre-forged alloy: (a) inverse pole figure map, (b) corresponding boundary misorientation map and (c) the enlarged image of the circular region A shown in (a).

Fig. 2 EBSD observation results of the pre-forged alloy just after heating at $350{ }^{\circ} \mathrm{C}$ and $400{ }^{\circ} \mathrm{C}$ for $5 \mathrm{~min}$ before extrusion: inverse pole figure maps and (0001) pole figures at (a) $350{ }^{\circ} \mathrm{C}$ and (b) $400{ }^{\circ} \mathrm{C}$, and corresponding (c) misoriention angle distribution and (d) grain size distribution.

Fig. 3 Inverse pole figure maps of the alloy extruded at $350{ }^{\circ} \mathrm{C}$ and $400{ }^{\circ} \mathrm{C}(\mathrm{a}, \mathrm{b})$ without and $(c, d)$ with pre-forging. White arrows indicate the coarse unDRXed grains elongated along the ED.

Fig. 4 TEM observation results of the alloy extruded at $350{ }^{\circ} \mathrm{C}$ (a-d) without and (e-f) with pre-forging: (a-c, e) BF images, (d) corresponding HAADF image of (c), (f) HAADF image of the rectangular region shown in (e), and (g-h) corresponding EDX elemental mappings of (f).

Fig. 5 TEM BF images showing dynamic precipitates (a, c) at DRXed GBs and (b, d) within grain interiors of the alloy extruded at $400{ }^{\circ} \mathrm{C}(\mathrm{a}, \mathrm{b})$ without pre-forging and $(\mathrm{c}$, d) with pre-forging. 
Fig. 6 Textures of the alloy extruded at $350{ }^{\circ} \mathrm{C}$ and $400{ }^{\circ} \mathrm{C}(\mathrm{a}-\mathrm{d})$ without and (e-h) with pre-forging: (a, c, e, g) (0001) pole figures and (b, d, f, h) separately highlighted crystallographic orientations of DRXed and unDRXed grains in (0001) pole figures and inverse pole figures. Here, the inverse pole figures refer to the ED.

Fig. 7 Low magnified optical microstructures at large area near the die exit of the alloy extruded at $400{ }^{\circ} \mathrm{C}$ without and with pre-forging.

Fig. 8 EBSD observation results at location of $5 \mathrm{~mm}$ to the die exit of the alloy extruded at $400{ }^{\circ} \mathrm{C}$ (a-d) without and (e-h) with pre-forging: (a, e) inverse pole figure maps, $(b, f)$ misorientation angle distributions, $(\mathrm{c}, \mathrm{g})$ line profiles of the misorientation angle along the black arrow (AB) in the unDRXed grains in (a, e), and (d, h) (0001) pole figures. Here, misorientation angle distributions and (0001) pole figures of the DRXed and unDRXed grains were separately analyzed from the examined full region.

Fig. 9 (a) Tensile and (b) compressive stress-strain curves of the alloy extruded at 350 ${ }^{\circ} \mathrm{C}$ and $400{ }^{\circ} \mathrm{C}$ without and with pre-forging.

Fig. 10 Schmid factor distribution histograms of the alloy extruded at $350{ }^{\circ} \mathrm{C}$ and 400 ${ }^{\circ} \mathrm{C}$ without and with pre-forging: (a) $(0001)<11 \overline{2} 0>$ basal slip when the tensile stress is along the ED, and (b) $(10 \overline{1} 2)<10 \overline{1} \overline{1}>$ extension twin when the compressive stress is along the ED.

Fig. 11 Optical microstructures of fractured tensile specimens of the alloy extruded at $350{ }^{\circ} \mathrm{C}$ and $400{ }^{\circ} \mathrm{C}$ without and with pre-forging. The red arrows indicate the microcracks initiated at twins formed within coarse unDRXed grains. 


\section{Table. 1}

Microstructural charateristics and mechanical properties of the alloy extruded at $350{ }^{\circ} \mathrm{C}$ and $400{ }^{\circ} \mathrm{C}$ without and with pre-forging.

\begin{tabular}{|c|c|c|c|c|c|c|c|c|c|}
\hline \multirow[t]{2}{*}{ Extruded alloy } & \multirow{2}{*}{$\begin{array}{l}\text { Extrusion } \\
\text { temperature }\left({ }^{\circ} \mathrm{C}\right)\end{array}$} & \multicolumn{3}{|c|}{ Microstructure } & \multicolumn{5}{|c|}{ Mechanical properties } \\
\hline & & 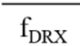 & $\mathrm{d}_{\mathrm{AGS}}(\mu \mathrm{m})$ & $\mathrm{d}_{\mathrm{DRX}}(\mu \mathrm{m})$ & TYS (MPa) & UTS (MPa) & EL (\%) & CYS (MPa) & CYS/TYS \\
\hline \multirow{2}{*}{ Without pre-forging } & $350^{\circ} \mathrm{C}$ & 0.66 & 18.3 & 3.1 & 283 & 295 & 10.0 & 154 & 0.54 \\
\hline & $400^{\circ} \mathrm{C}$ & 0.85 & 30.7 & 12.2 & 161 & 233 & 24.7 & 111 & 0.69 \\
\hline \multirow{2}{*}{ With pre-forging } & $350^{\circ} \mathrm{C}$ & 0.98 & 4.3 & 3.7 & 254 & 284 & 27.9 & 190 & 0.75 \\
\hline & $400{ }^{\circ} \mathrm{C}$ & 1.00 & 9.7 & 9.7 & 181 & 248 & 34.8 & 134 & 0.74 \\
\hline
\end{tabular}

$f_{D R X}, d_{A G S}$ and $d_{D R X}$ represent the DRX fraction, average grain size and DRXed grain size, respectively. 

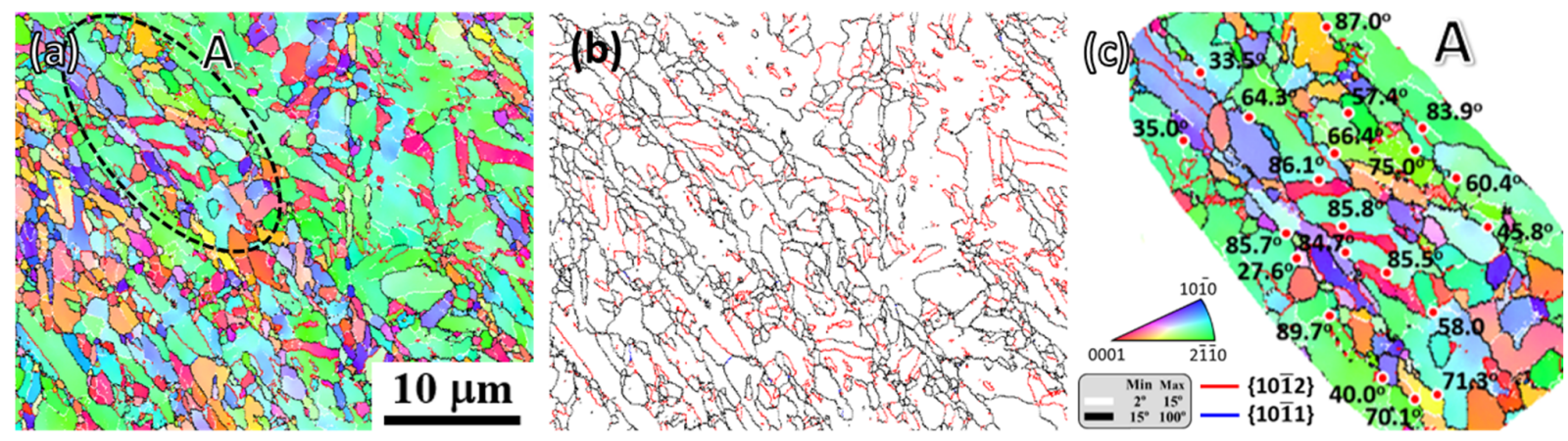

Fig. 1 EBSD observation results of the pre-forged alloy: (a) inverse pole figure map, (b) corresponding boundary misorientation map and (c) the enlarged image of the circular region A shown in (a).

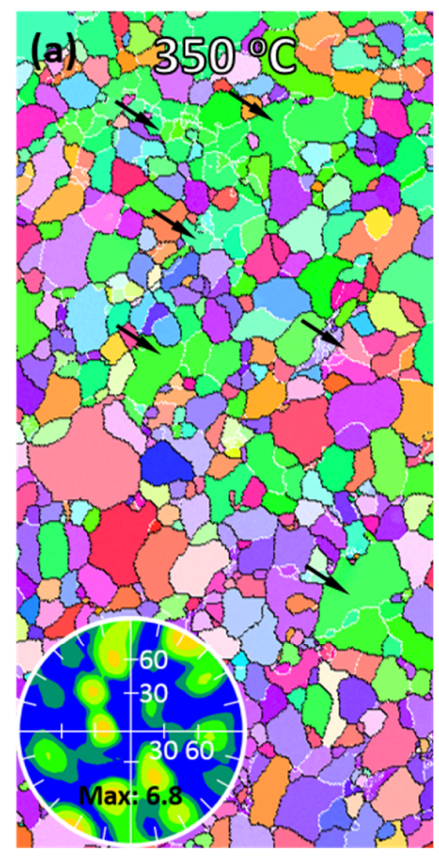

Texture intensity

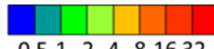

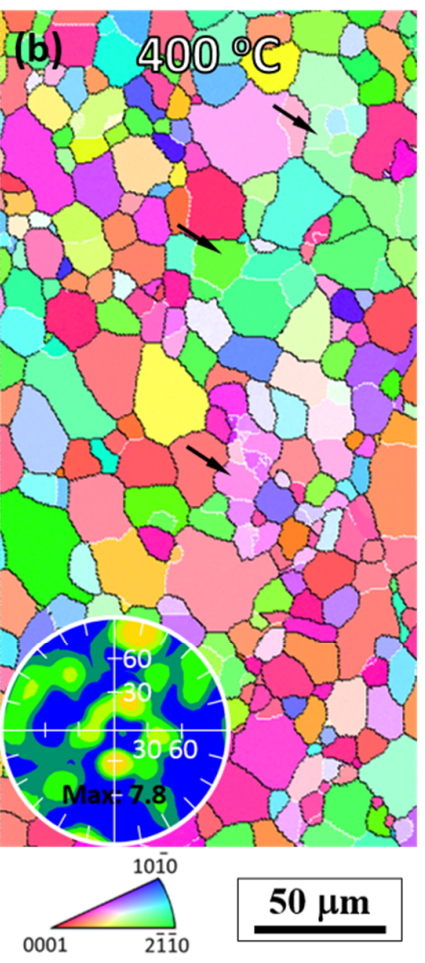

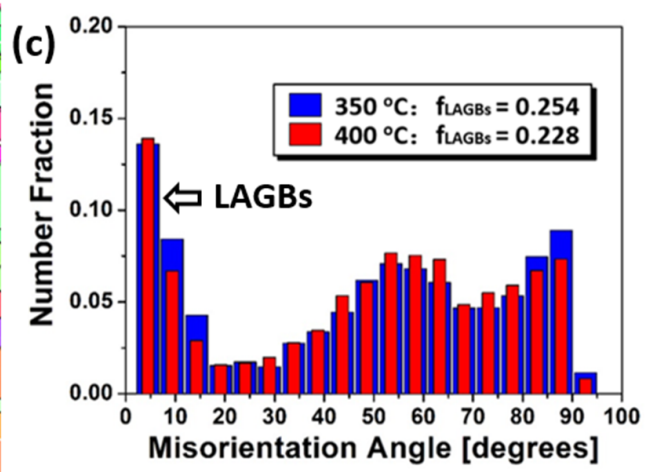

(d)

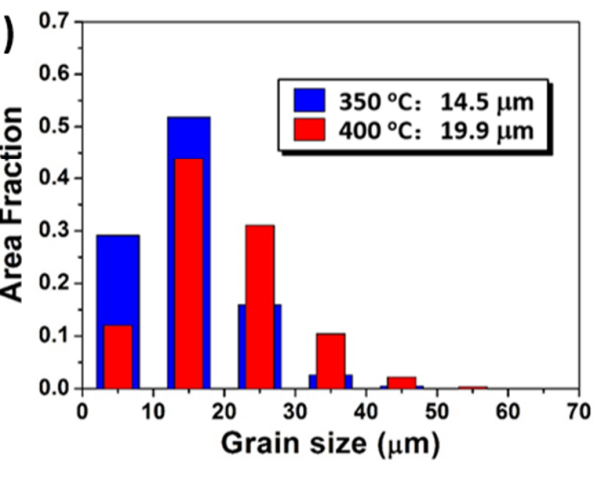

Fig. 2 EBSD observation results of the pre-forged alloy just after heating at $350{ }^{\circ} \mathrm{C}$ and $400{ }^{\circ} \mathrm{C}$ for $5 \mathrm{~min}$ before extrusion: inverse pole figure maps and (0001) pole figures at (a) $350{ }^{\circ} \mathrm{C}$ and (b) 400 ${ }^{\circ} \mathrm{C}$, and corresponding (c) misoriention angle distribution and (d) grain size distribution. 


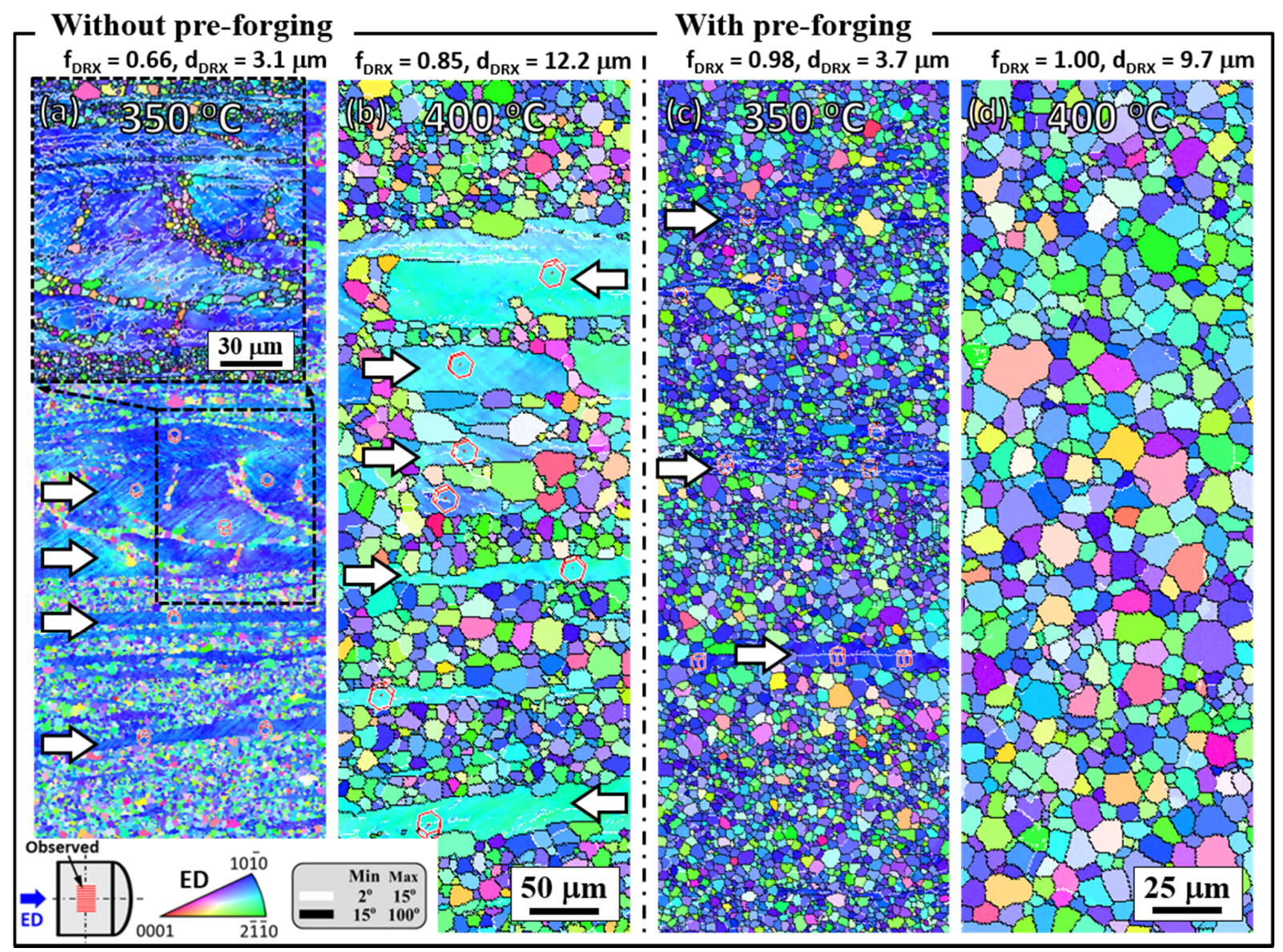

Fig. 3 Inverse pole figure maps of the alloy extruded at $350{ }^{\circ} \mathrm{C}$ and $400{ }^{\circ} \mathrm{C}(\mathrm{a}, \mathrm{b})$ without and $(\mathrm{c}, \mathrm{d})$ with pre-forging. White arrows indicate the coarse unDRXed grains elongated along the ED. 


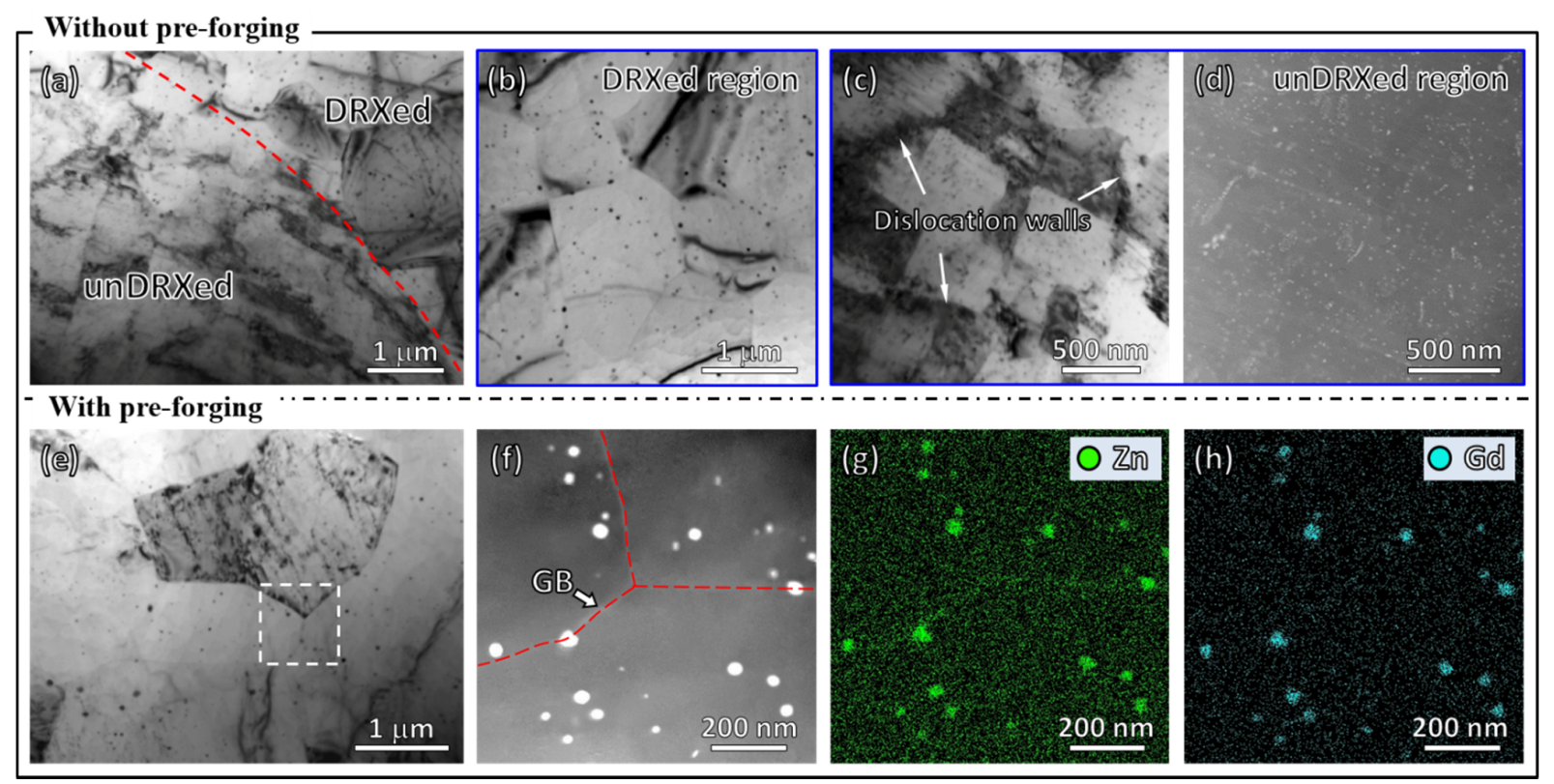

Fig. 4 TEM observation results of the alloy extruded at $350{ }^{\circ} \mathrm{C}$ (a-d) without and (e-f) with pre-forging: (a-c, e) BF images, (d) corresponding HAADF image of (c), (f) HAADF image of the rectangular region shown in (e), and (g-h) corresponding EDX elemental mappings of (f).

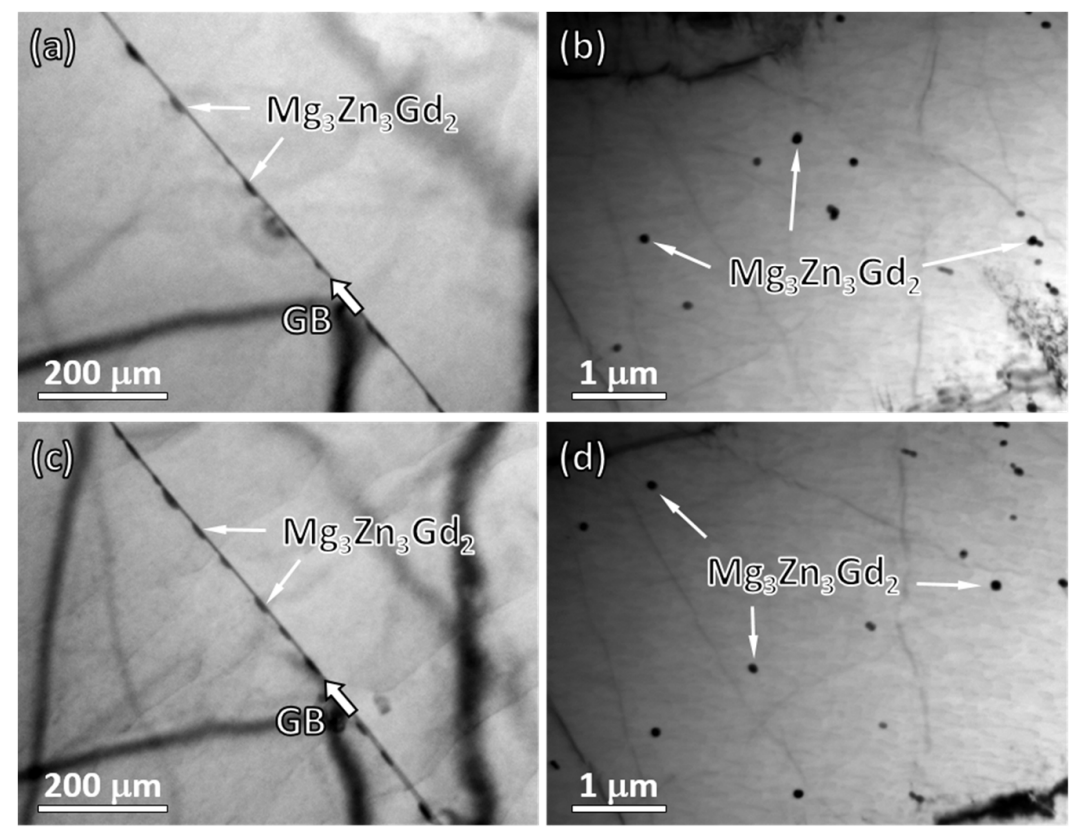

Fig. 5 TEM BF images showing dynamic precipitates (a, c) at DRXed GBs and (b, d) within grain interiors of the alloy extruded at $400{ }^{\circ} \mathrm{C}(\mathrm{a}, \mathrm{b})$ without pre-forging and (c, d) with pre-forging. 


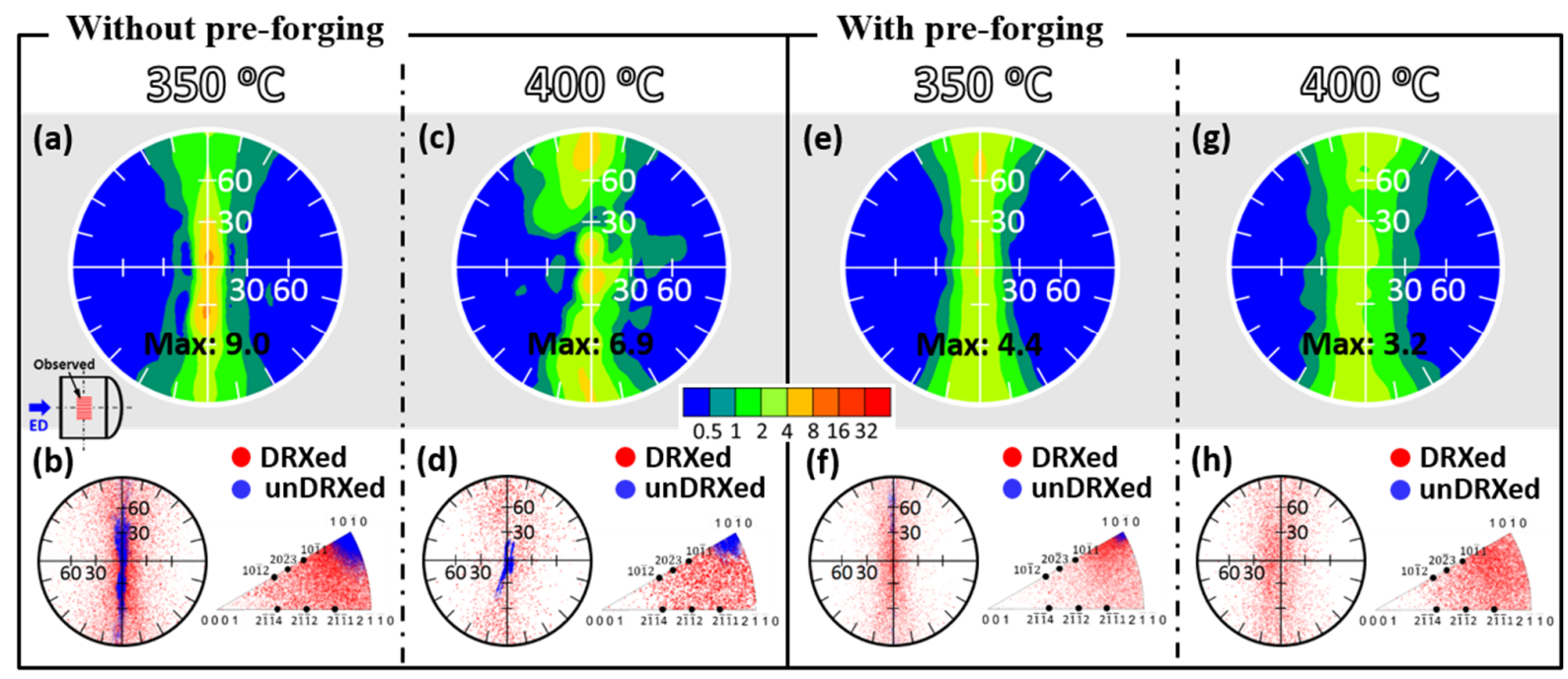

Fig. 6 Textures of the alloy extruded at $350{ }^{\circ} \mathrm{C}$ and $400{ }^{\circ} \mathrm{C}(\mathrm{a}-\mathrm{d})$ without and (e-h) with pre-forging: (a, c, e, g) (0001) pole figures and (b, d, f, h) separately highlighted crystallographic orientations of DRXed and unDRXed grains in (0001) pole figures and inverse pole figures. Here, the inverse pole figures refer to the ED.
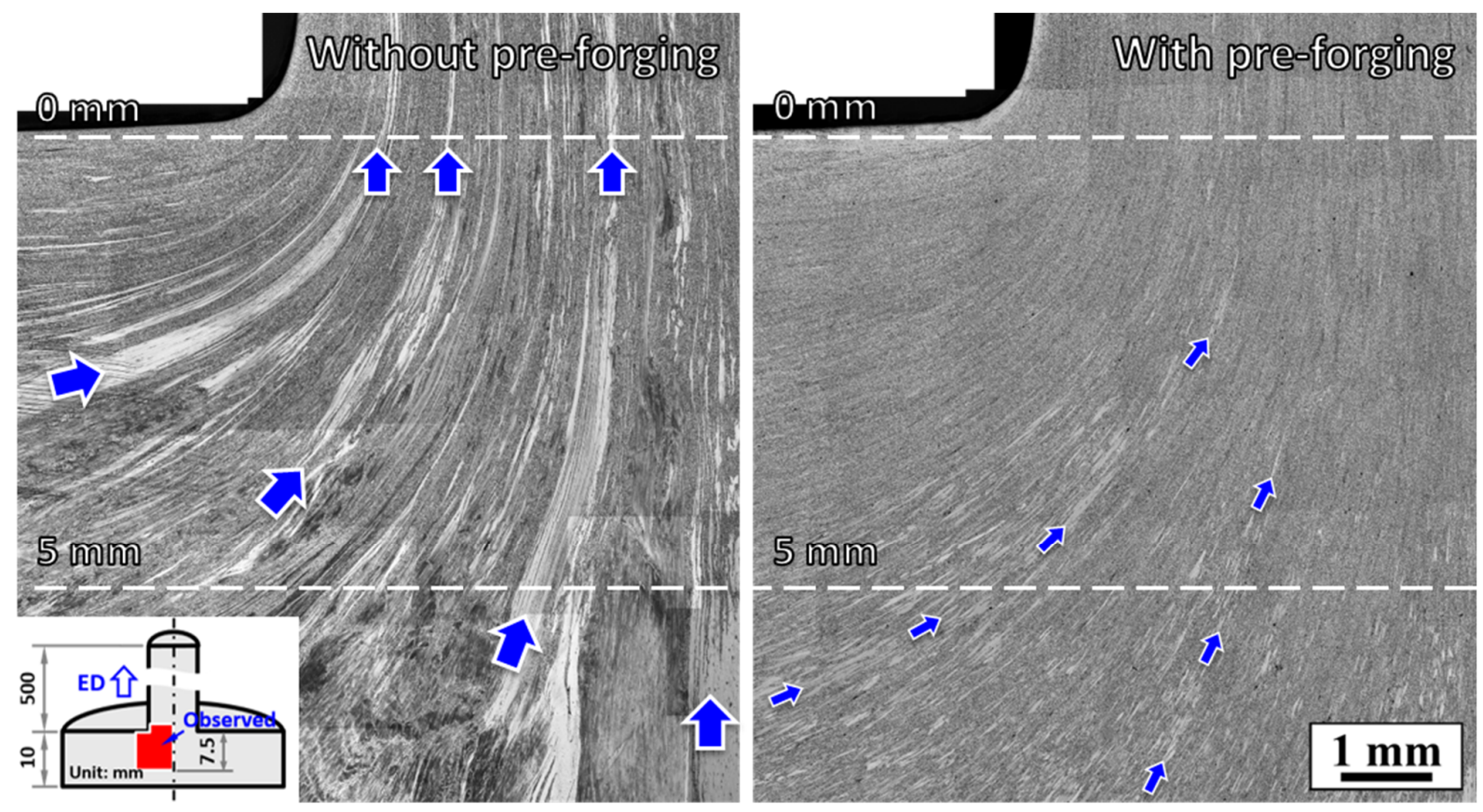

Fig. 7 Low magnified optical microstructures at large area near the die exit of the alloy extruded at $400{ }^{\circ} \mathrm{C}$ without and with pre-forging. 
Without pre-forging

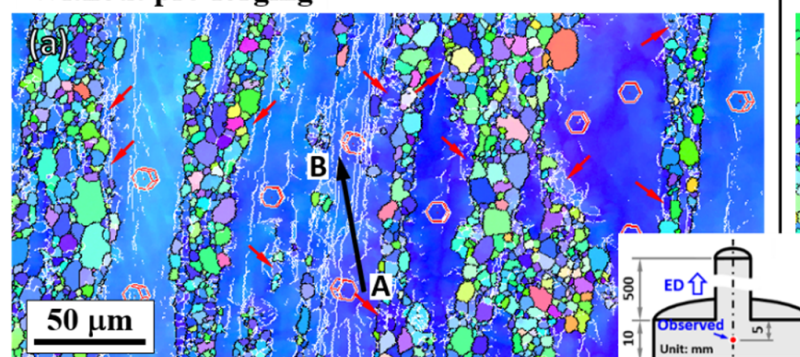

With pre-forging

$(\text { b })_{0.8} \quad$ (c)

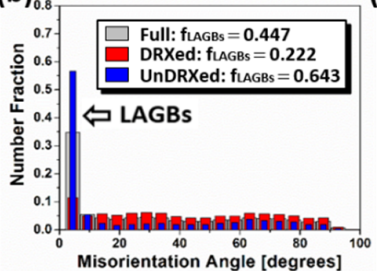

(c) 30
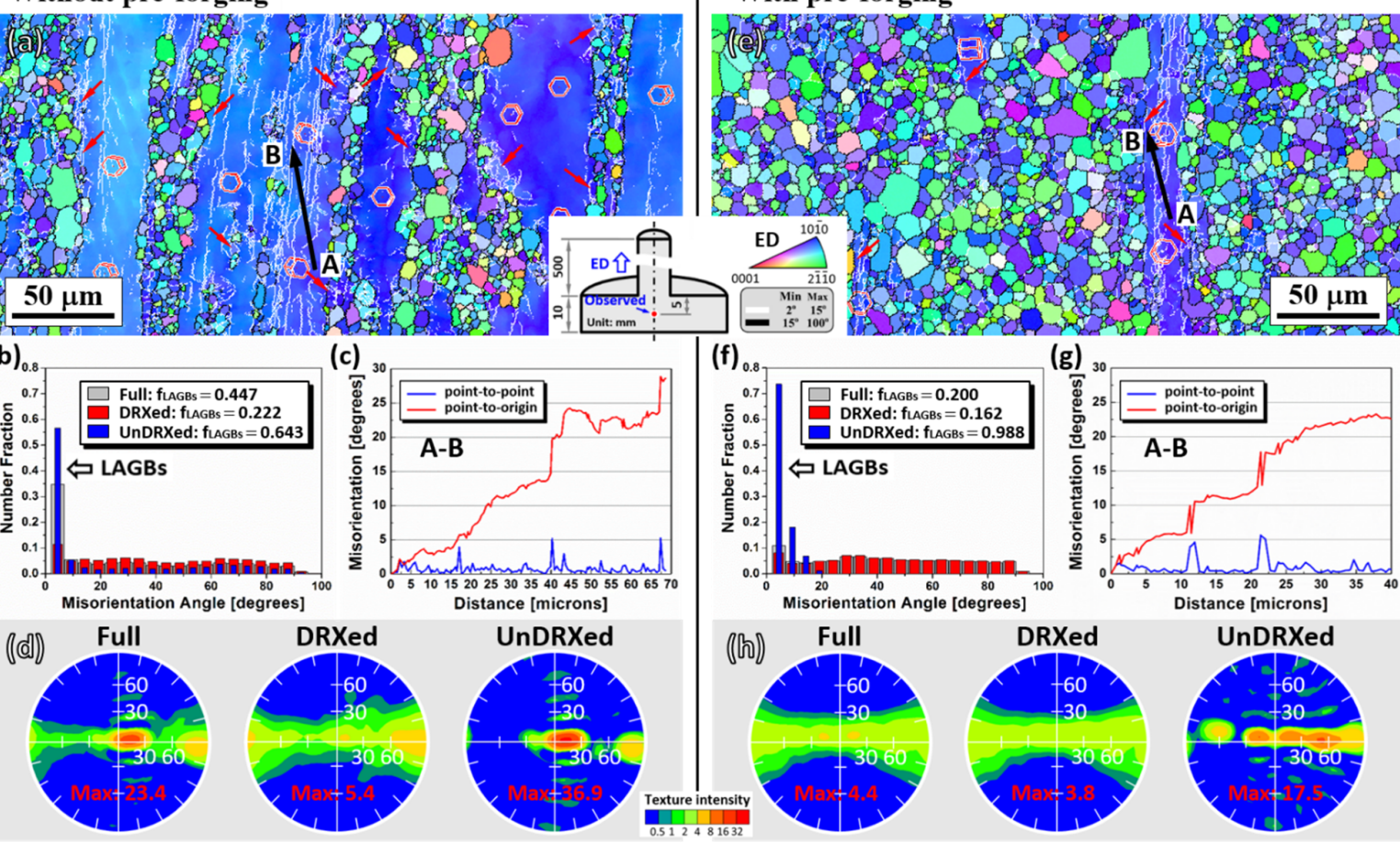

DRXed

Distance [microns]

$(\mathbf{f})_{0.8}$

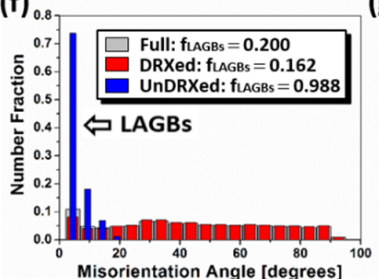

(g)
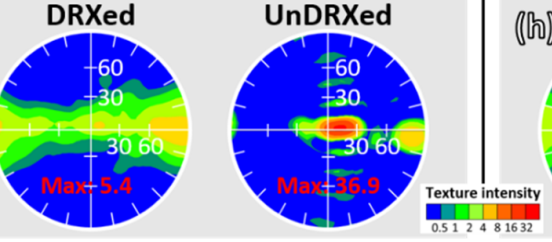

([))

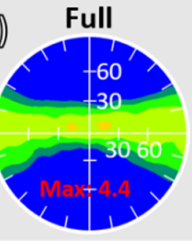

DRXed

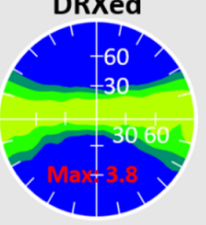

UnDRXed

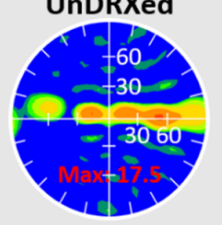

Fig. 8 EBSD observation results at location of $5 \mathrm{~mm}$ to the die exit of the alloy extruded at $400{ }^{\circ} \mathrm{C}$ (a-d) without and (e-h) with pre-forging: (a, e) inverse pole figure maps, (b, f) misorientation angle distributions, $(\mathrm{c}, \mathrm{g})$ line profiles of the misorientation angle along the black arrow $(\mathrm{AB})$ in the unDRXed grains in $(\mathrm{a}, \mathrm{e})$, and $(\mathrm{d}, \mathrm{h})(0001)$ pole figures. Here, misorientation angle distributions and (0001) pole figures of the DRXed and unDRXed grains were separately analyzed from the examined full region. 

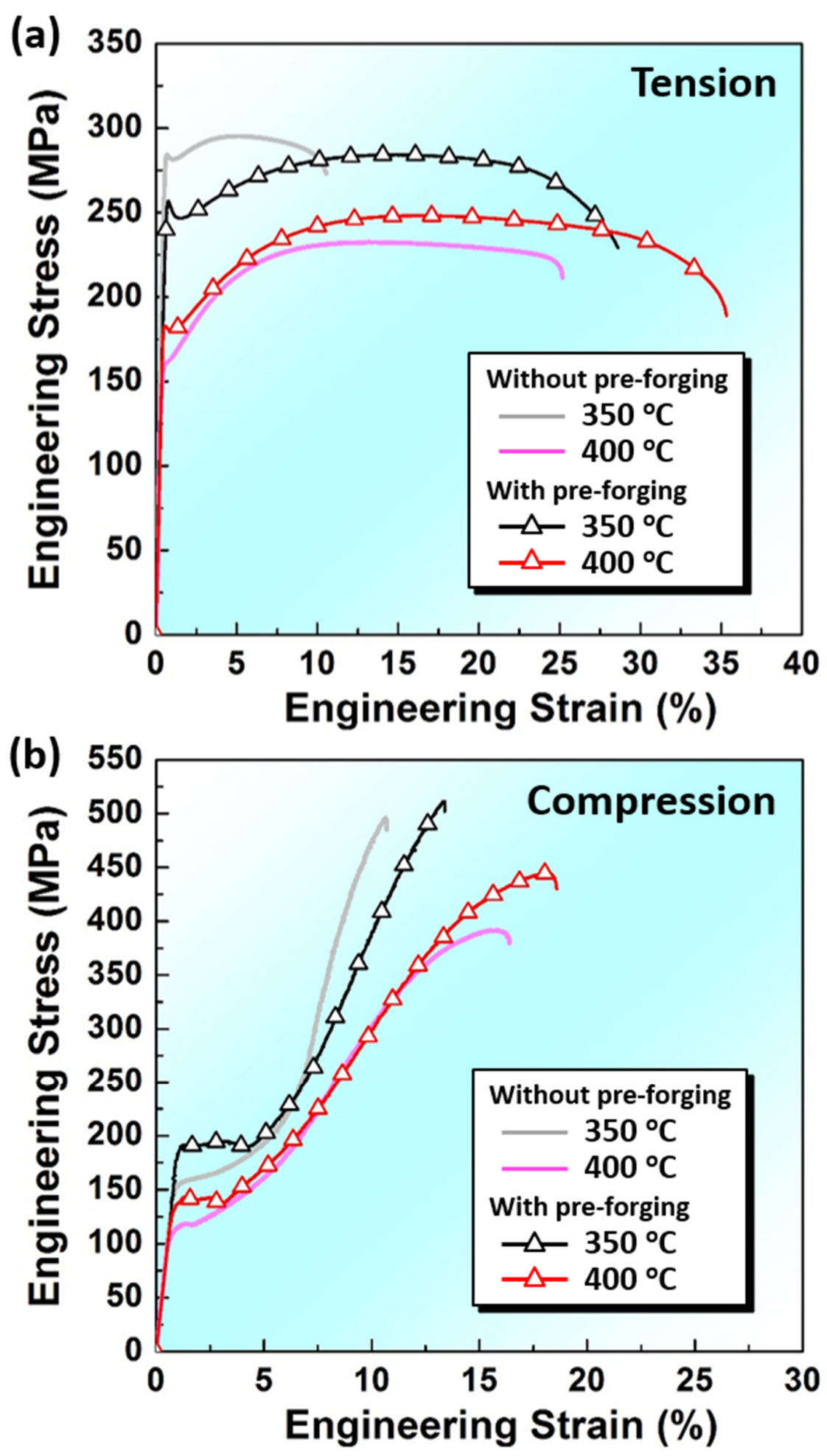

Fig. 9 (a) Tensile and (b) compressive stress-strain curves of the alloy extruded at $350{ }^{\circ} \mathrm{C}$ and 400 ${ }^{\circ} \mathrm{C}$ without and with pre-forging. 

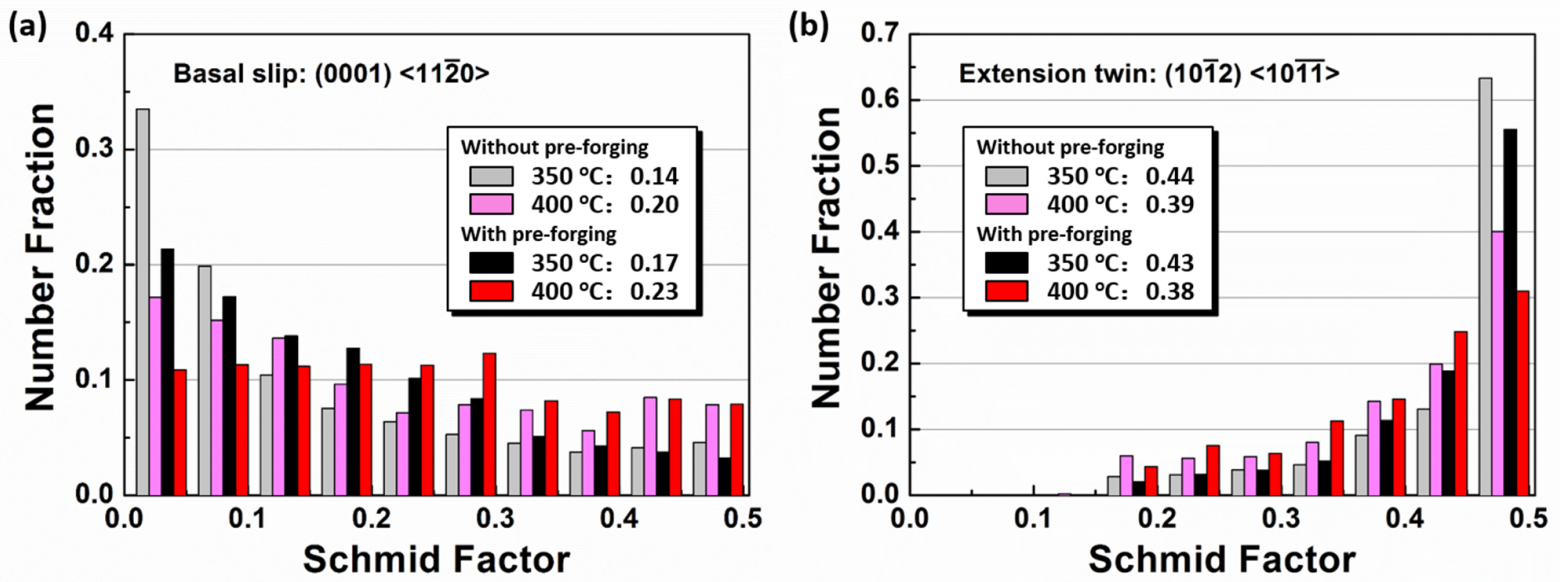

Fig. 10 Schmid factor distribution histograms of the alloy extruded at $350{ }^{\circ} \mathrm{C}$ and $400{ }^{\circ} \mathrm{C}$ without and with pre-forging: (a) $(0001)<11 \overline{2} 0>$ basal slip when the tensile stress is along the ED, and (b) $(10 \overline{1} 2)<10 \overline{1} \overline{1}>$ extension twin when the compressive stress is along the ED.

Without pre-forging

With pre-forging
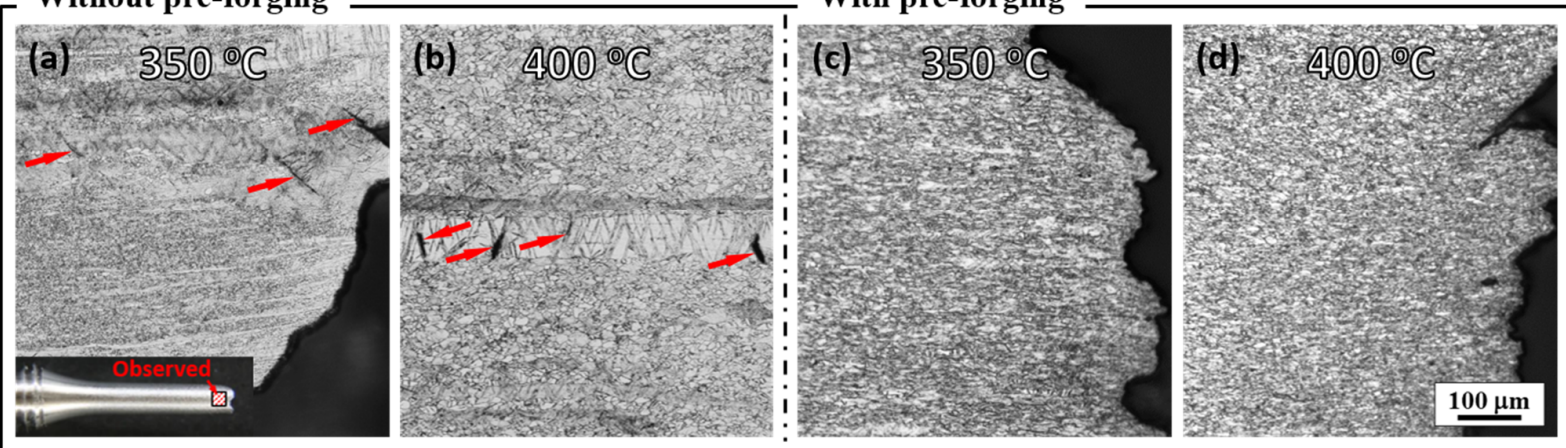

Fig. 11 Optical microstructures of fractured tensile specimens of the alloy extruded at $350{ }^{\circ} \mathrm{C}$ and $400{ }^{\circ} \mathrm{C}$ without and with pre-forging. The red arrows indicate the microcracks initiated at twins formed within coarse unDRXed grains. 


\section{Graphical Abstract}

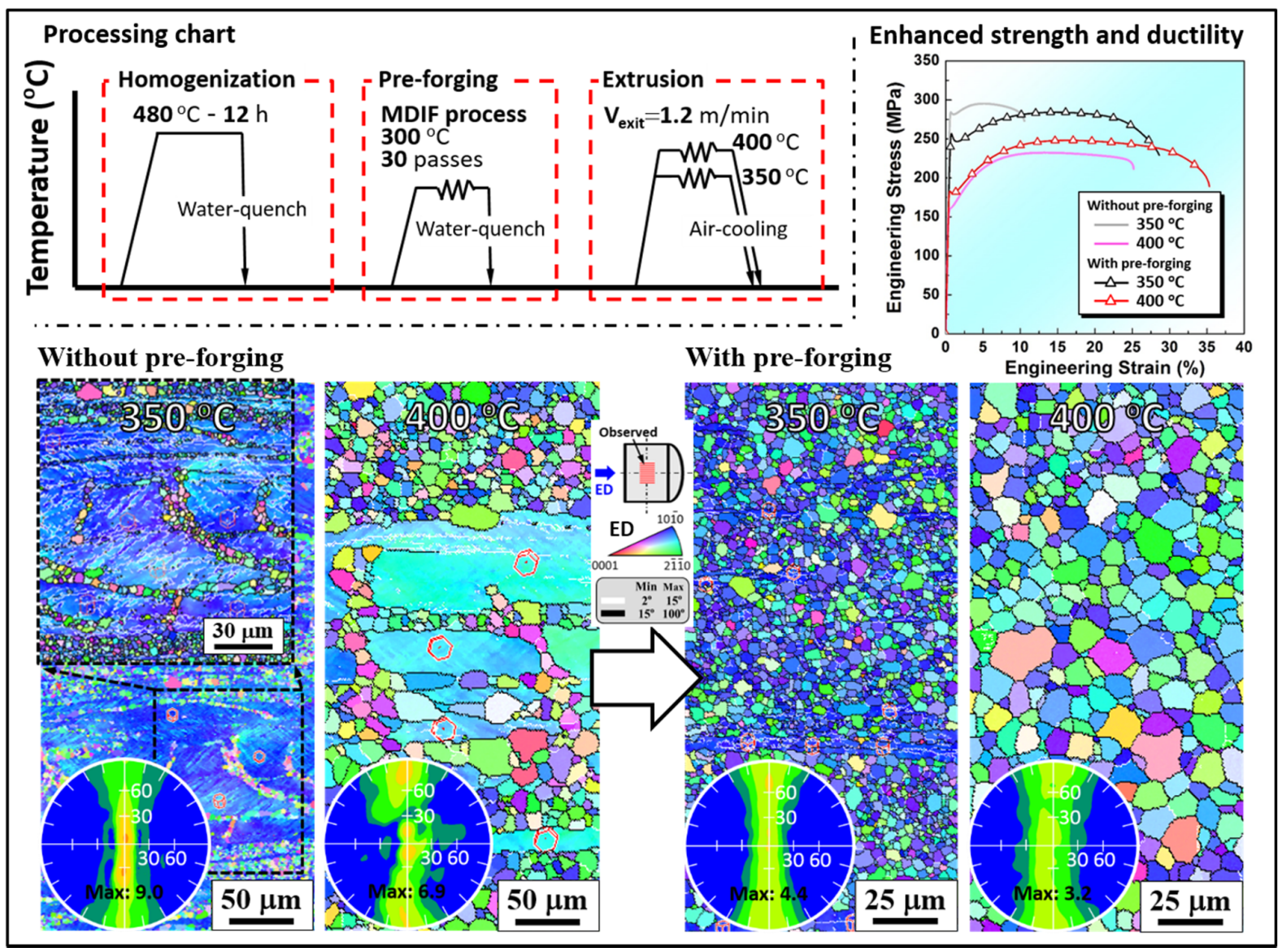

